\title{
Very Compact and Broadband Active Antenna for VHF Band Applications
}

\author{
Y. Taachouche, F. Colombel, and M. Himdi \\ Institut d'Electronique et de Télécommunication de Rennes, Université de Rennes 1, UMR CNRS 6164, 263 avenue, \\ Général Leclerc, 35042 Rennes, France \\ Correspondence should be addressed to Y. Taachouche, yaakoub.taachouche@univ-rennes1.fr
}

Received 14 September 2011; Revised 12 December 2011; Accepted 12 December 2011

Academic Editor: Mandeep Jit Singh

Copyright ( $\odot 2012$ Y. Taachouche et al. This is an open access article distributed under the Creative Commons Attribution License, which permits unrestricted use, distribution, and reproduction in any medium, provided the original work is properly cited.

An active receiving antenna with small size consisting of a monopole loaded with a transistor bipolar is presented in this paper. A transistor is used in order to miniaturize the receiving active antenna size in VHF band. The vertical size of the structure is equal to $\lambda / 175$, where $\lambda$ is the wavelength at the lower frequency of the bandwidth. Despite the very small size of the antenna, the frequency bandwidth is very wide and the gain is suitable for FM application with sensitive receivers.

\section{Introduction}

Miniaturized and broadband antennas with omnidirectional coverage have attracted attention for industrial applications. One of the major challenges is the integration of antennas inside devices including many systems in a limited area. For example, today's mobile phones are innovative devices that provide a wide variety of services to users. One of the most attractive mobile phone services is the entertainment service, and specially the functionality that allows users to listen to FM radios through their mobile phones. This development induces a growing demand of FM antennas for mobile phones and the necessity of innovative technologies to develop internal small FM antennas, which replace the external wire antennas that exhibit current mobile phones in the market. For automobile application, where many radio systems work as communication systems, FM radio reception is collocated on the top roof of the car, and the very low visual impact of the antenna is required. The goal of this paper is to propose a compact antenna to replace the historical monopole to improve the integration capability of the antenna in VHF band applications systems.

Many passive antennas such as monopole, dipole, and printed antenna have been largely studied to yield small size relatively to the wavelength or broadband behaviour.
Previous studies have shown that antenna miniaturization impacts negatively antenna bandwidth and impedance matching [1]. After the invention of high frequency transistor, the study of active antenna has really started at the beginning of the 1960s [2]. As it is mentioned in [3, 4], active antenna provides new opportunities for many applications including increase of bandwidth or size reduction.

As explained in [2], a practical integrated design is a transistorized dipole, which is a combination of a resonant half wavelength dipole and a VHF transistor. This combination between a radiating element and an active component provides high gain and size reduction of $\lambda / 53$. In [5], a fed emitter base loop dipole has been proposed as a transmitting antenna. A total height of $\lambda / 2000$ instead of $\lambda / 2$ antenna has been built and compared with a passive dipole of equal height. The active antenna is very broadband and is able to operate at very low frequencies with very small size. In [58 ], it has been explained that an active monopole fed by a microwave transistor is able to provide a greater frequency bandwidth than a passive monopole. For example, in [6], the variation of input impedance of an active antenna over the range $0.77-1.45 \mathrm{GHz}$ is explained.

In order to provide innovative design, the growing interest for active antennas has required more accurate analysis method. A hybrid analysis including electromagnetic full wave and nonlinear circuit solver is used in [9] and provided 


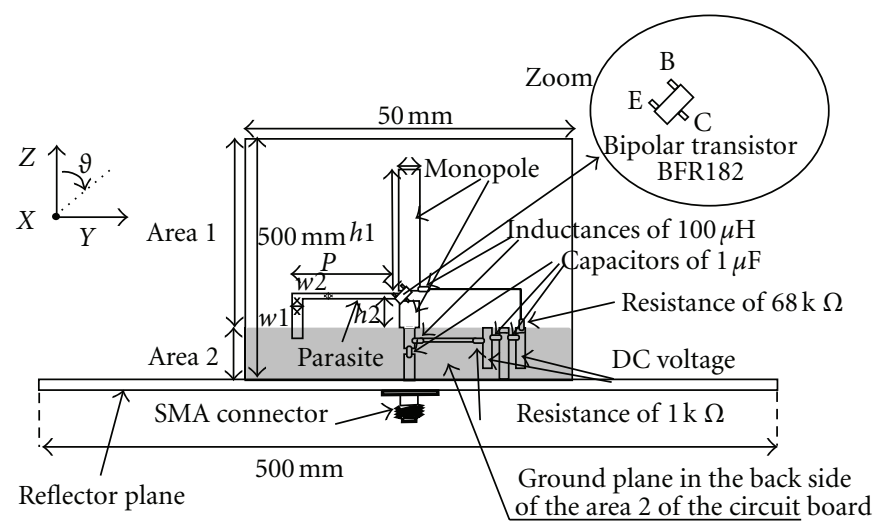

(a) Front view

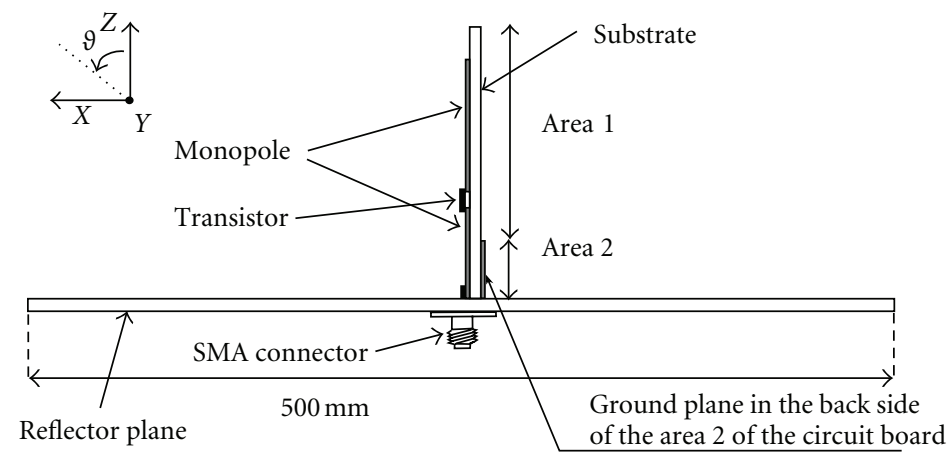

(b) Side view

Figure 1: Geometry of the proposed active receiving antenna $(h 1=25 \mathrm{~mm}, h 2=5 \mathrm{~mm}, P=20 \mathrm{~mm}, w=4 \mathrm{~mm}, w 1=2 \mathrm{~mm}, w 2=1 \mathrm{~mm})$.

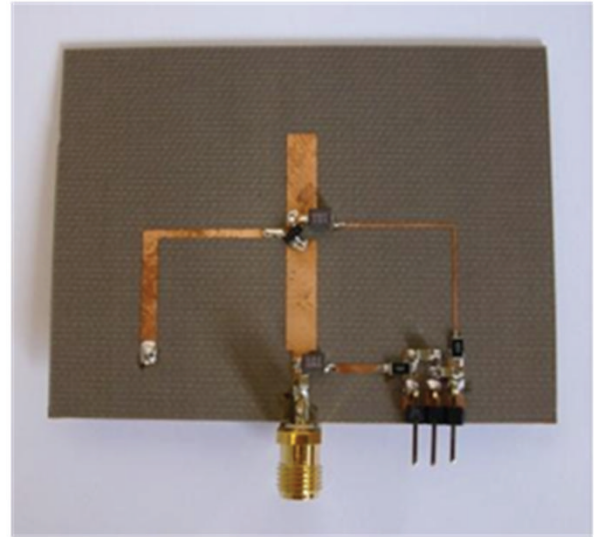

(a)

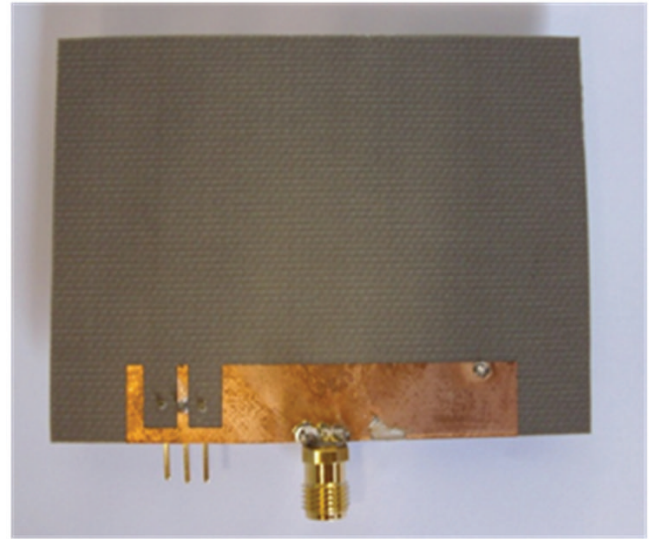

(b)

FIgure 2: Prototype of the active receiving antenna: (a) front view, (b) back view with the limited ground plane.

accurate theoretical validated with measurements on an oscillator active antenna.

In this paper, we are interested in the improvements brought by the active antennas towards size reduction and we propose an active antenna based on a printed monopole associated to a bipolar transistor. In the first part, we present the antenna design including the bias circuit. In the second part, we have carried out a theoretical and experimental study of an active receiving antenna in VHF band including reflection coefficient and radiation pattern measurements. The theoretical approach is based on a hybrid method where the electromagnetic full wave software CST is used.

\section{Design of the Active Antenna}

The structure of the active receiving antenna is shown in Figure 1. The antenna is a combination of a monopole and a high frequency bipolar transistor (BFR182). The antenna has 


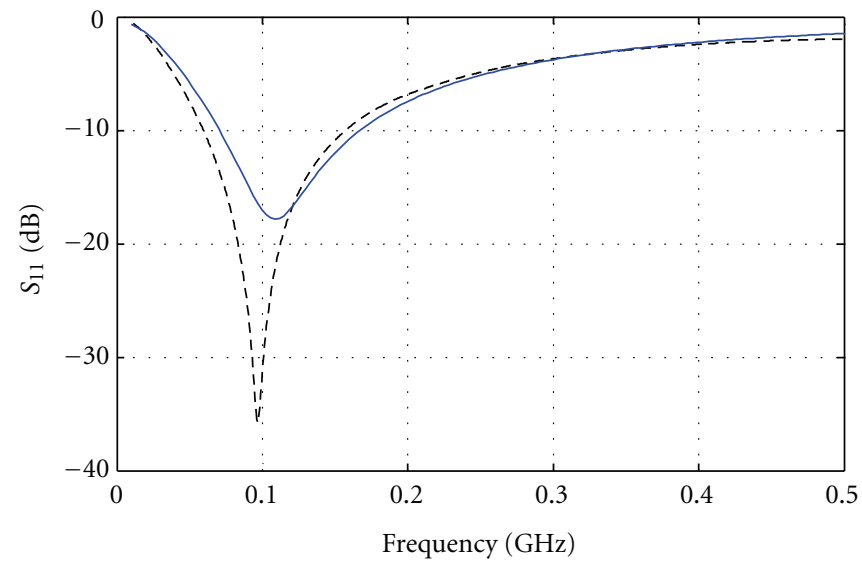

(a)

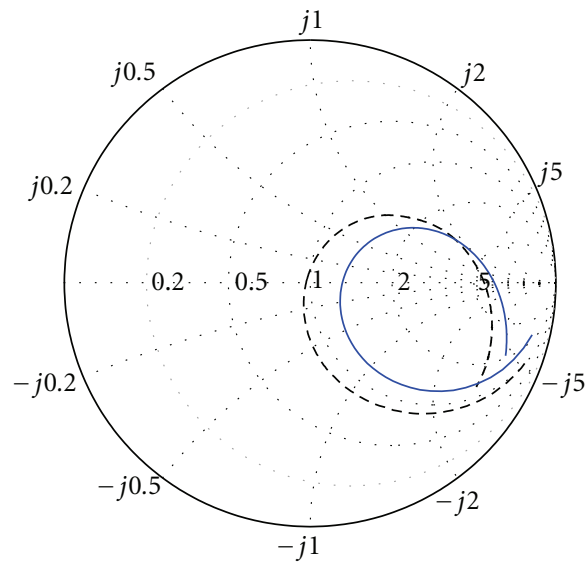

(b)

FIGURE 3: (a) Simulated and measured $S_{11}$ of the active receiving antenna. (b) Simulated and measured input impedances of the active receiving antenna $(10-500 \mathrm{MHz})$ (dashed line) measured, (solid line) simulated.

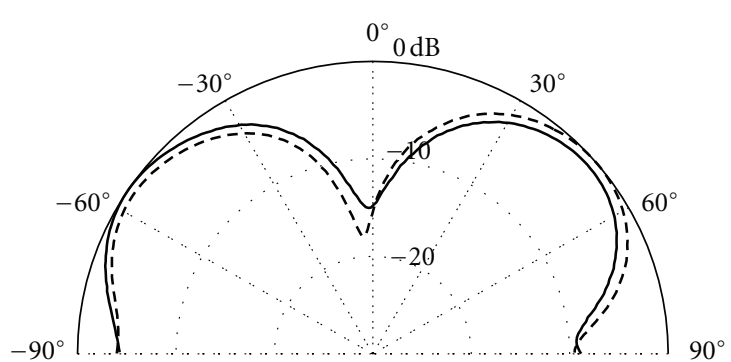

(a)

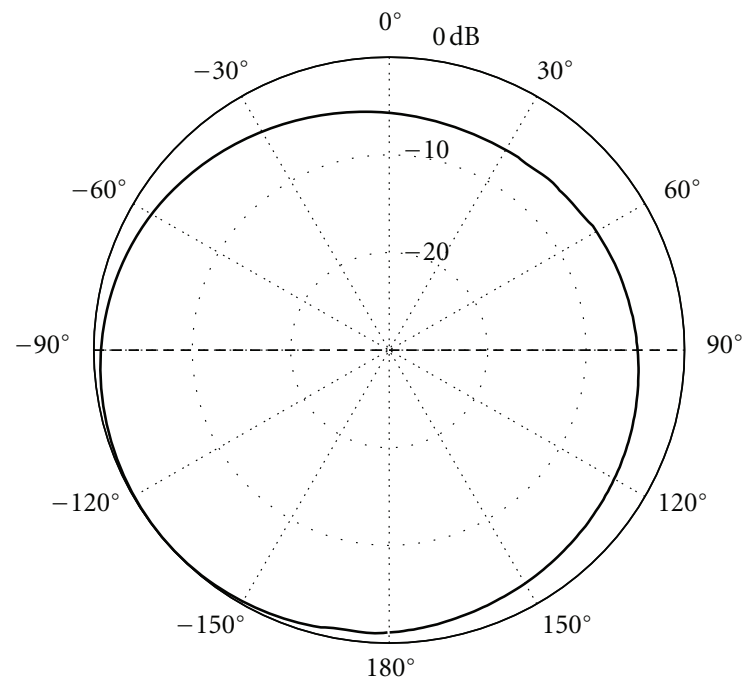

(c)

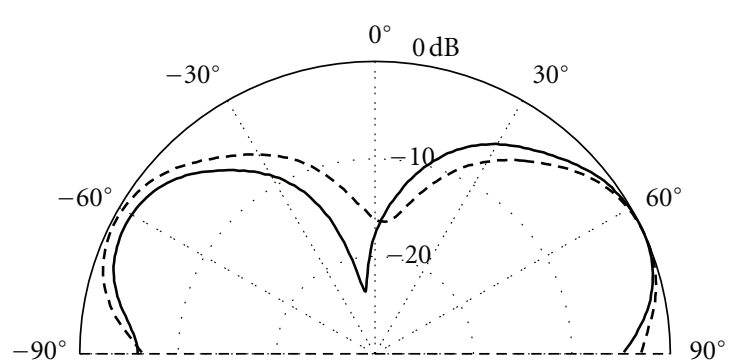

(b)

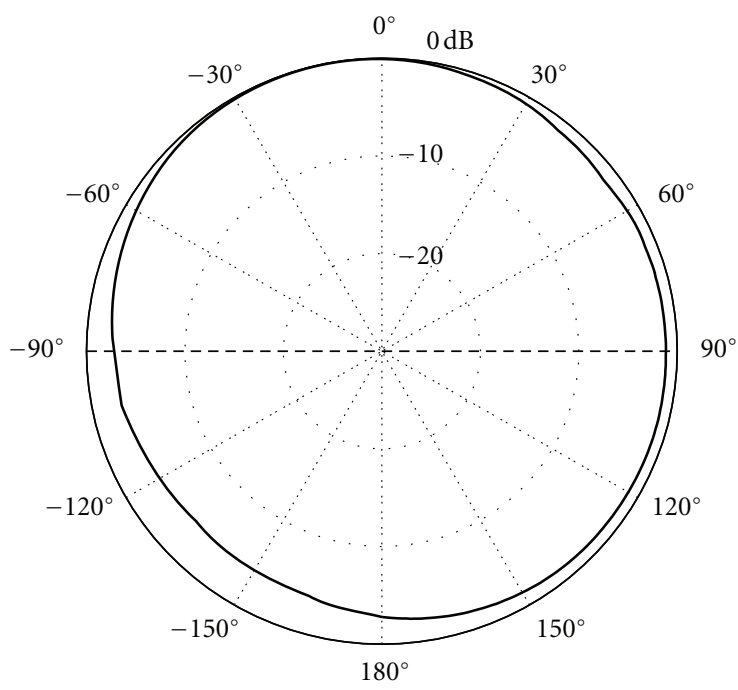

(d)

FIgURE 4: Measured normalized radiation patterns in H-plane, E-plane. (a) E-plane at $80 \mathrm{MHz}$ for solid line $\varphi=0^{\circ}$ dashed line $\varphi=90^{\circ}$, (b) E-plane at $100 \mathrm{MHz}$ for solid line $\varphi=0^{\circ}$ dashed line $\varphi=90^{\circ}$, (c) H-plane at $80 \mathrm{MHz}$ for $\theta=90^{\circ}$, and (d) $\mathrm{H}$-plane at $100 \mathrm{MHz}$ for $\theta=90^{\circ}$.

been printed on a Neltec NX9300 substrate $\left(\varepsilon_{r}=3, h=\right.$ $0.786 \mathrm{~mm}, \tan \delta=0.0023$ ) and is placed above a limited square reflector plane $\left(500 \times 500 \times 4 \mathrm{~mm}^{3}\right)$. As shown in Figure 1, the monopole has been cut into two parts and the bipolar transistor BFR 182 is directly integrated between these two parts of the monopole without matching circuit. The antenna is connected to an SMA connector through a 50 $\Omega$ microstrip line.

The BFR182 transistor is a PNP bipolar transistor for low-noise and high-gain broadband amplifier applications, 
and works up to $8 \mathrm{GHz}$. It is used in common emitter configuration as an amplifier. The emitter of the transistor is grounded through the parasitic printed line, the transistor base and collector are linked to the upper part and to the bottom part of the monopole, respectively. We can also notice that the bias circuit of the transistor is located on the left side of the monopole. The transistor is located at $5 \mathrm{~mm}$ over the ground plane (1/6 of the height of the monopole). The optimized dimensions of the proposed antenna are reported in Figure 1 to obtain the optimum gain and bandwidth. In order to isolate the DC voltage from RF signal, two chokes $(\mathrm{L} 1=\mathrm{L} 2=100 \mu \mathrm{H})$ are located in the base and in the collector of the transistor, respectively. C3, C4, and $\mathrm{C} 2$ are decoupling capacitors of $1 \mu \mathrm{F}$ each. The value of the resistances $(\mathrm{R} 1=1 \mathrm{k} \Omega, \mathrm{R} 2=68 \mathrm{k} \Omega)$ has been calculated in order to obtain the collector to emitter voltage (Vce) and collector current (Ic) of Vce $=8 \mathrm{~V}$ and Ic $=10 \mathrm{~mA}$.

Figure 2 shows the prototype of the active antenna built for the measurements.

\section{Results}

In this section, we present simulated and measured results obtained from the active receiving antenna which operates in VHF band. In the simulation of the active antenna, we combine the results of the electromagnetic calculation of the antenna with electrical calculation of the bias circuit of the transistor. It conducts to a full analysis of the active antenna [9]. This simulation was performed with CST Microwave Studio.

In Figure 3, we show the reflection coefficient and the impedance of the proposed antenna between $10 \mathrm{MHz}$ and $500 \mathrm{MHz}$. Even if there is a shift between theory and measurement, the results are still in good agreement. We can explain these discrepancies with the difference between the theoretical parameters of the transistor provided by the PSPICE model and the real one. The measurements exhibit a $-10 \mathrm{~dB}$ bandwidth of $94 \%$ around $107.5 \mathrm{MHz}$. The height of the active antenna is close to $\lambda / 175$, where $\lambda$ is the wavelength at the lowest operating frequency $(57 \mathrm{MHz})$.

These measurements results are very interesting towards the size of the receiving antenna compared to previous contribution [2], where the height of the active antenna was $56 \mathrm{~cm}$. This height was equal to $\lambda / 53$ at $10 \mathrm{MHz}$. As a result, the $-10 \mathrm{~dB}$ bandwidth of our antenna is close to $94 \%$. It is also an achievement because regarding passive antenna, the size reduction often implies narrow frequency band. For example, in [10] the passive handset antenna design for FM reception has been presented with $\mathrm{a}-3 \mathrm{~dB}$ bandwidth equal to $15.5 \%$ and a gain of $-18.7 \mathrm{dBi}$.

In Figure 4, we presented the measured radiation patterns of the proposed antenna in the E-plane $\left(\varphi=0^{\circ}\right)$ and in H-plane $\left(\varphi=90^{\circ}\right)$ at $80 \mathrm{MHz}$ and $100 \mathrm{MHz}$. The plots show nearly omnidirectional patterns in the $\mathrm{H}$-plane with ripples of $6.36 \mathrm{~dB}$ at $80 \mathrm{MHz}$ and $4.4 \mathrm{~dB}$ at $100 \mathrm{MHz}$. The E-planes exhibit symmetrical radiation patterns.

The measured gain of the active receiving antenna at $80 \mathrm{MHz}$ is $-23.39 \mathrm{dBi}$ and $-19.6 \mathrm{dBi}$ at $100 \mathrm{MHz}$. The gain values correspond to the maximal gain obtained in the
E-planes. This gain value is very low but should be comparable with a passive antenna with the same height. We have not measured this monopole, we have just simulated it and we found a low theoretical gain close to $-49 \mathrm{dBi}$.

\section{Conclusion}

A very small active receiving antenna has been investigated with a bandwidth of $94 \%$ around $107.5 \mathrm{MHz}$. The active receiving antenna is based on a monopole structure associated to a transistor. The vertical size of the structure is close to $\lambda / 175$, where $\lambda$ is the wavelength at the lowest frequency of the bandwidth. Simulations and measurements are in good agreement. The measured gain of the active receiving antenna at $100 \mathrm{MHz}$ is $-19.6 \mathrm{dBi}$. The very high sensitivity of VHF receivers, for example, in FM band, allows applications when a very low visual impact of the antenna is required.

\section{References}

[1] H. A. Wheeler, "Fundamental limitations of small antennas," Proceedings of the IRE, vol. 35, no. 4, pp. 1479-1484, 1947.

[2] H. H. Meinke, Transistorized Receiving Antennas, Institut fur Hochfrequenztechnik der Technischen Hochschule, Munchen, Germany, 1967.

[3] Y. Qian and T. Itoh, "Progress in active integrated antennas and their applications," IEEE Transactions on Microwave Theory and Techniques, vol. 46, no. 11, pp. 1891-1900, 1998.

[4] K. Chang, R. A. York, P. S. Hall, and T. Itoh, "Active integrated antennas," IEEE Transactions on Microwave Theory and Techniques, vol. 50, no. 3, pp. 937-943, 2002.

[5] T. S. M. Maclean and G. Morris, "Short active transmitting antenna with very large height reduction," IEEE Transactions on Antennas and Propagation, vol. 23, no. 2, pp. 286-287, 1975.

[6] A. P. Anderson and M. Dawoud, "The performance of transistor fed monopoles in active antennas," IEEE Transactions on Antennas and Propagation, vol. 21, no. 3, pp. 371-374, 1973.

[7] P. A. Ramsdale and T. S. M. Maclean, "Active loop-dipole aerials," Proceedings of the Institution of Electrical Engineers, vol. 118, no. 12, pp. 1698-1710, 1971.

[8] J. Copeland, W. Robertson, and R. Verstraete, "Antennafier arrays," IEEE Transactions on Antennas and Propagation, vol. 12, no. 2, pp. 227-233, 1964.

[9] R. G. Ertürk, P. Rojas, and Roblin, "Hybrid analysis/design method for active integrated antennas," IEE Proceedings of Microwaves, Antennas and Propagation, vol. 146, no. 2, pp. 131-137, 1999.

[10] J. Anguera, D. Aguilar, J. Vergés, M. Ribó, and C. Puente, "Hanset antenna design for FM reception," in Proceedings of the IEEE Antennas and Propagation Society International Symposium, San Diego, Calif, USA, 2008. 

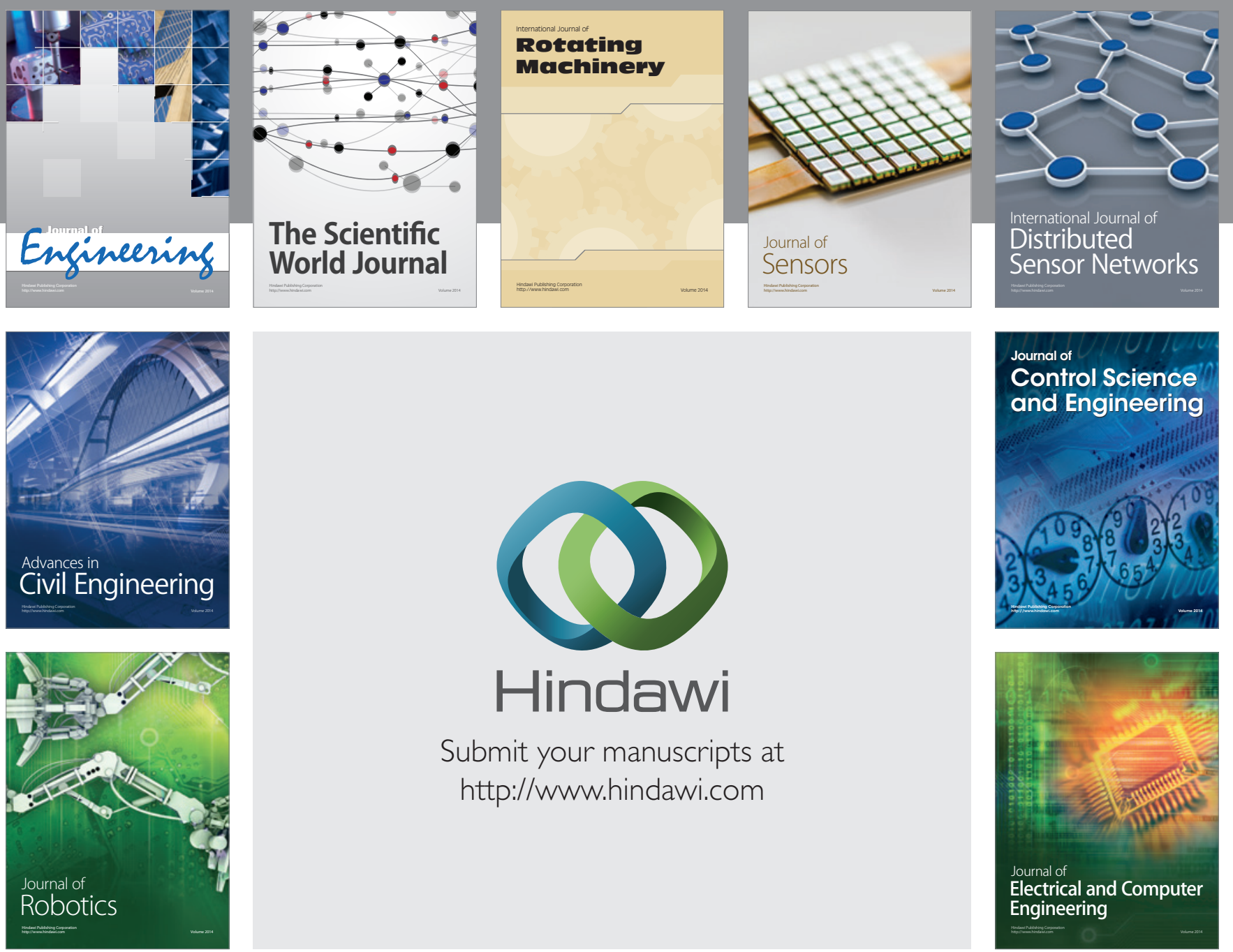

Submit your manuscripts at

http://www.hindawi.com
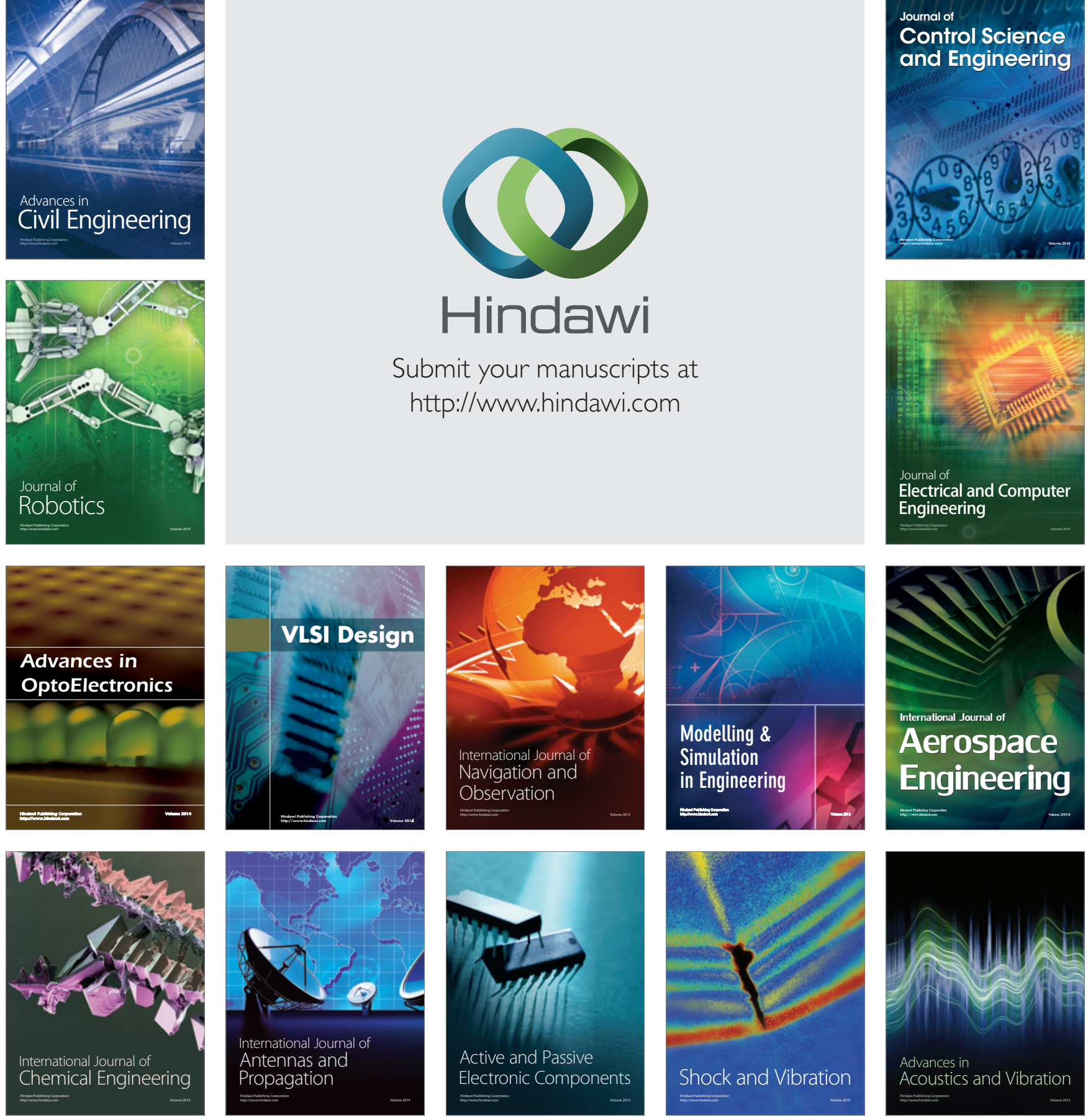